\title{
A NEW TORQUE CONTROL SYSTEM OF PERMANENT MAGNET SYNCHRONOUS MOTOR
}

\author{
Andrey Evstratov ${ }^{1,}$, , Valery Zavyalov $^{1}$, Alexander Grigoryev $^{2}$,and Irina Semykina ${ }^{1,2}$ \\ ${ }^{1}$ Kuzbass State Technical University, 650000 Kemerovo, Russia \\ ${ }^{2}$ Tomsk Polytechnic University, 634050 Tomsk, Russia
}

\begin{abstract}
The article describes a new approach to control of permanent magnet synchronous motor drive based on the analysis of the electromechanical transformation. The proposed control system provides quick response and low ripple of the motor torque and flux. To synthesis this control system, the authors put the electromagnetic torque and the modulus of stator flux vector as controlled values and use the Lyapunov's second method. In addition, the stator voltage constriction and ability of low-pass filtration are taken into account. The investigation of the proposed control system has carried out with the simulation and the experimental research which have confirmed that the proposed control system correspond to all above-mentioned control tasks and the permanent magnet synchronous motor controlled under this system may be recommended to use in robotics.
\end{abstract}

\section{Introduction}

A permanent magnet synchronous motor (PMSM) is a type of electric motor having a low mass and inertia and also small time constants that nowadays become widely used as a input force source, for example in robotics.

There are many researches dealing with PMSM control system [1-17] that may be classified by optimization criteria: the minimum time [4, 5, 7, 8, 10-12, 17], the minimum loss $[2,16]$, the minimum torque ripple $[1,3,6,9,17]$ and the minimum flux ripple $[11$, 17]. The new torque control system of PMSM with quick response and low ripple, which match well with robotics tasks, is given below.

\section{The control approach}

To obtain the controlling of PMSM dynamic state and the energy optimization of motor, the control system regulates the electromagnetic torque $T$ and the modulus of stator flux vector $\psi_{s}$ :

\footnotetext{
* Corresponding author: eaegemf@mail.ru
} 


$$
\mathbf{Y}^{*}-\mathbf{Y} \rightarrow 0, \mathbf{Y}=\left[\begin{array}{l}
y_{1} \\
y_{2}
\end{array}\right]=\left[\begin{array}{c}
T \\
\psi_{s}
\end{array}\right] .
$$

13.5 liters), was manufactured from optical glass of thickness $5 \mathrm{~mm}$. A solution of castor oil in ethyl alcohol in different percent ratios and glycerin were used as liquids; soft soap was used as surfactant.

$$
V=\left[\mathbf{Y}^{*}-\mathbf{Y}\right]^{T} \mathbf{1}\left[\mathbf{Y}^{*}-\mathbf{Y}\right]=\sum_{i=1}^{2}\left(y_{i}^{*}-y_{i}\right)^{2}
$$

By virtue of the fact that $V$ is the positive definite function, the negative value of its derivative $d V / d t$ certifies $V \rightarrow 0$ when $t \rightarrow \infty$ meaning $\mathbf{Y} \rightarrow \mathbf{Y}^{*}$. The model of PMSM with nonsalient pole in the $d, q$ reference frame is defined the follow equation [13]:

$$
\begin{gathered}
u_{s d}=\frac{d \psi_{s d}}{d t}+i_{s d} R+p \omega \psi_{s q} ; u_{s q}=\frac{d \psi_{s q}}{d t}+i_{s q} R-p \omega \psi_{s d} ; \\
\psi_{s d}=L i_{s d}+\lambda ; \psi_{s q}=L i_{s q} ; M=(3 / 2) p \lambda i_{s q} ; J \frac{d \omega}{d t}=T-T_{l},
\end{gathered}
$$

where $\lambda$ is the rotor flux; $u_{s d}, u_{s q}, i_{s d}, i_{s q}, \psi_{s d}, \psi_{s q}$ are the vector components of the stator voltage the stator current and the stator flux correspondingly; $L$ is the stator inductance; $R$ is the stator resistance; $p$ is the number of pole pair; $T_{l}$ is the load torque; $J$ is the rotor inertia; $\omega$ is the rotor speed. So, the conditions of $d V / d t$ negativity is obtained by means expression of $d V / d t$ from (1) using (2):

$$
\frac{\left(T^{*}-T\right)}{T_{n}}\left(\frac{3}{2} p e_{s q} \frac{\lambda}{L}\right)+\frac{\left(\psi_{s}^{*}-\psi_{s}\right)}{\psi_{s n}}\left(e_{s d} \frac{L i_{s d}+\lambda}{\psi_{s}}+e_{s q} \frac{L i_{s q}}{\psi_{s}}\right)>0,
$$

where $e_{s d}, e_{s q}$ are the vector components of the stator EMF calculated as $e_{s d}=d \psi_{s d} / d t, e_{s q}=$ $d \psi_{s q} / d t ; T_{n}, \psi_{s n}$ are the nominal values of the electromagnetic torque and the modulus of stator flux vector.

On the assumption with the stator voltage is constraint, the applying of the positive maximum voltage $u_{s d \max }$ and $u_{s q \max }$ force the stator EMF $e_{s d}$ and $e_{s q}$ to be positive, and the opposite is true. Given that point the analysis of (3) leads to the conclusion to satisfy the inequality the PMSM control system should form the stator voltage as:

$$
u_{s q}=\left\{\begin{array}{l}
u_{s q \max }, \text { if } \frac{\left(T^{*}-T\right)}{T_{n}} \frac{3}{2} p \frac{\lambda}{L}+\frac{\left(\psi_{s}^{*}-\psi_{s}\right)}{\psi_{s n}} \frac{L i_{s q}}{\psi_{s}}>0 ; \\
-u_{s q \max }, \text { if } \frac{\left(T^{*}-T\right)}{T_{n}} \frac{3}{2} p \frac{\lambda}{L}+\frac{\left(\psi_{s}^{*}-\psi_{s}\right)}{\psi_{s n}} \frac{L i_{s q}}{\psi_{s}}<0 ; \\
u_{s d \max }, \text { if } \frac{\left(\psi_{s}^{*}-\psi_{s}\right)}{\psi_{s n}} \frac{L i_{s d}+\lambda}{\psi_{s}}>0 ; \\
-u_{s d \max }, \text { if } \frac{\left(\psi_{s}^{*}-\psi_{s}\right)}{\psi_{s n}} \frac{L i_{s d}+\lambda}{\psi_{s}}<0 .
\end{array}\right.
$$

\section{The control system investigation}

To investigate the dynamic performance of proposed control system the simulation and experimental research was carried out. The object of research was PMSM with capacity of 
$2.2 \mathrm{~kW}$ and the next parameters: $L=0.022 \mathrm{H}, J=0.055 \mathrm{~kg} \cdot \mathrm{m}^{2}, \lambda=0.393 \mathrm{~Wb}, R=2.7 \Omega$. This PMSM was supplied by pulse width modulated voltage source transistor converter with the switching frequency of $5 \mathrm{kHz}$.

The simulation result of the control system with (4) showed the mean values of $T$ and $\psi_{s}$ was controlled with the required accuracy, however there was high-level ripples in the amount $32.68 \%$ from $T_{n}$ and $5.5 \%$ from $\psi_{s n}$. Such ripples is caused of the voltage converter use only $u_{s d \max }$ и $u_{s q \max }$ and not to apply intermediate values of the stator voltage.

To decrease the torque ripples the low-pass filter was put in the control system. Fig. 1 shows its final structure, and fig. 2 displays the results of its simulation that testify the ripple reduction to $16.39 \%$ for electromagnetic torque and $1.39 \%$ for the modulus of stator flux vector. In addition, it have to be noted the low-pass filter was not affect on the transient time, which is $0.005 \mathrm{~s}$ for the PMSM with non-exited stator in the initial state.

The experimental research was carried out to compare results with simulation.

The experimental installation consist of the PMSM with MBS-FC01 frequency converter, TRB-5K torque sensor and the loading direct current motor. MBS-FC01 frequency converter is the coverless pulse width modulated voltage source transistor converter with open software supported platform based on TMS320F28335 microcontroller by Texas Instruments and the intelligent power unit. The converter's software powered by MexBIOS real-time operating system and MexBIOS Development Studio graphical programming environment.

To examine the behaviors obtained via simulation PMSM was tested the next way: loaded start and start under no-load conditions, step injection of load torque after starting and reversion of motion (fig. 3).

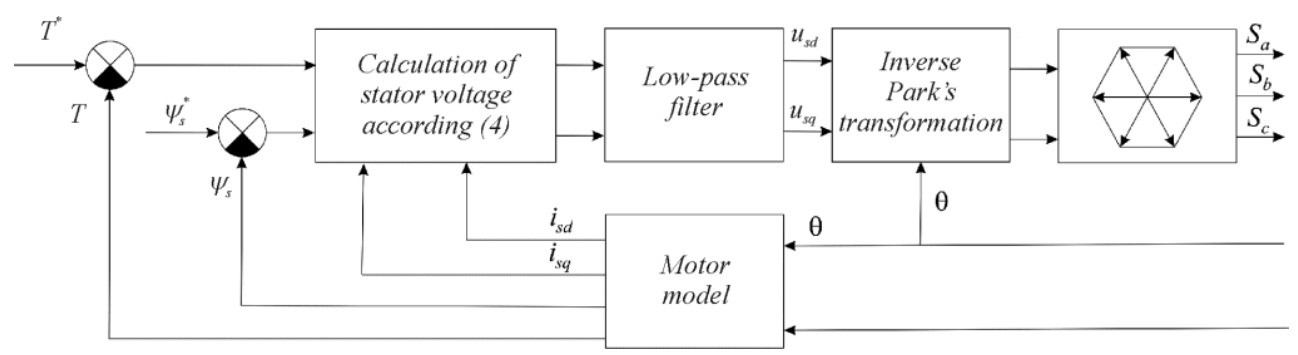

Fig. 1. The structure of proposed control system.
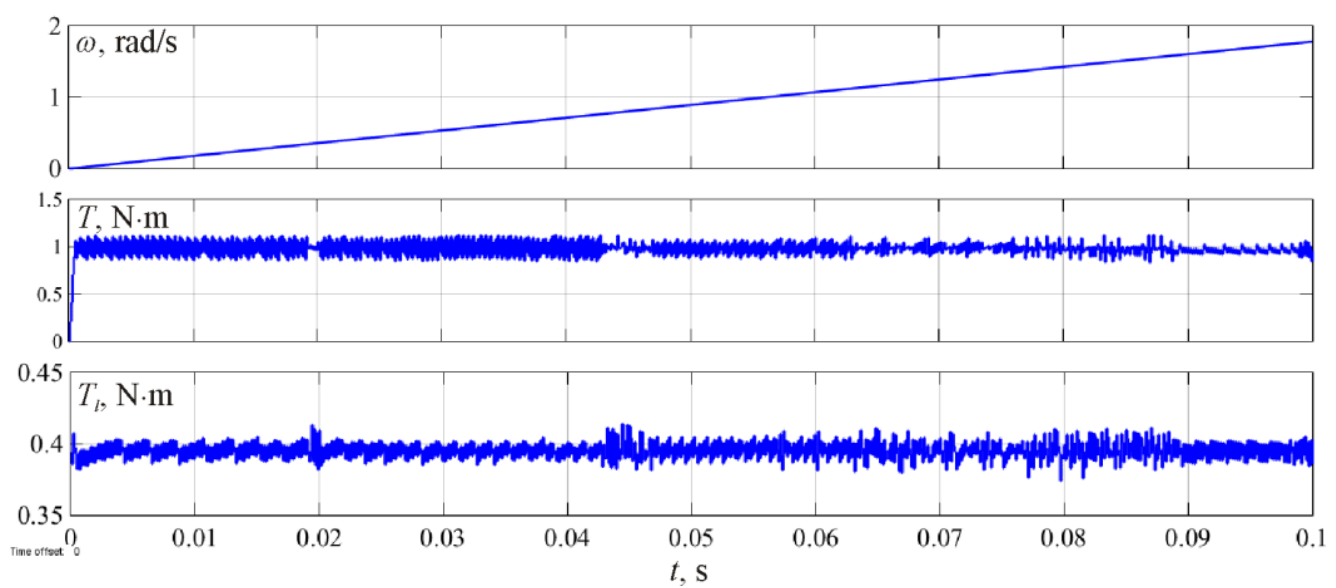

Fig. 2. The simulation results of proposed control system. 


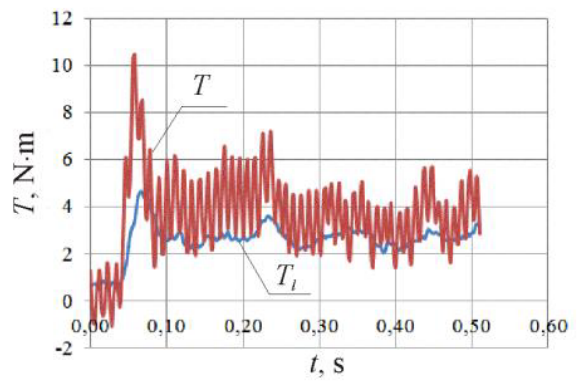

a

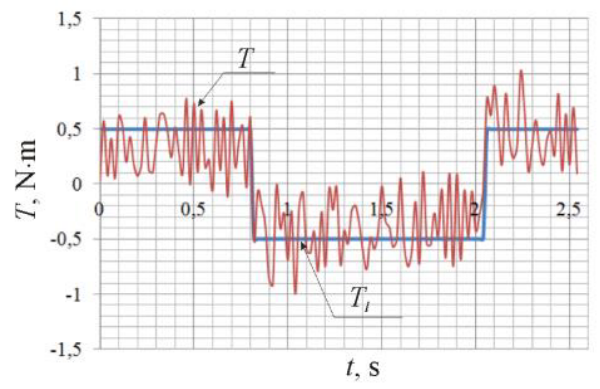

b

Fig. 3. The results of experimental research: $a-$ loaded start; $b$ - reverse.

\section{Conclusion}

The results depicted on fig. 3 have high-level ripples, however this ripples caused not the control system but the noises from analog-digital conversion of sensors' data explained by crosslinks. The carried research confirmed the proposed control system correspond to all above-mentioned tasks, and PMSM controlled under it may be recommended to use in robotics.

\section{References}

1. T. D. Batzel, K. Y. Lee, IEEE Trans. Energy Convers. 13, 257 (1998)

2. C. Bizot, J. Brottes, M. Lungeanu, B. Poulsen, D. Séra, M. Sørensen, Sensorless Control for PMSM. Power Electronics and Drives, Institute of Energy Technology, Aalborg University, Denmark, (2003)

3. S. Bouchiker, G. A. Capolino, M. Poloujadoff, IEEE Transactions Power Electronics 13, 1089 (1998)

4. H. Chaoui, P. Sicard, IEEE Trans. Ind. Electron. 59,1123 (2012)

5. K. Chikh, A. Saad, M. Khafallah, D. Yousfi, Canadian Journal on Electrical and Electronics Engineering 2, 400 (2011)

6. M. L. Corradini, G. Ippoliti, S. Longhi, G. Orlando,Sliding Mode Approach for Robust 59, 1096 (2012)

7. Gabriel Noriega, Miguel Strefezza, Wseas Transactions. Electronics 11, 2452 (2007)

8. Jian Wang, Honghua Wang, Tianhang Lu, Dehong Teng, ICEMS, 110 (2011)

9. Kyeong-Hwa Kim, In-Cheol Baik, Gun-Woo Moon, Myung-Joong Youn, IEEE Trans, on Control System technology 7, 630 (1997)

10. M. Kadjoudj, S. Taibi, N. Golea, International Journal of Sciences and Techniques of Automatic control \&computer engineering 1, 167 (2007)

11. Y. A. Mohamed, IEEE Transactions Power Electronics 22, 2042 (2007)

12. Y .A. Mohamed, IEEE Transactions Industrial Electronics 54, (1981)

13. P. Pillay, R. Krishnan, IEEE Transactions Industry Applications 25, 265 (1989)

14. T. Takeshita, N. Matsui, EMF Constant Identifier. IECON 1, 8 (1994)

15. C Edwards, S Spurgeon. Sliding Mode Control: Theory And Application. CRC Press Reference, (Taylor \& Francis, London, 1998) 